\title{
Update 2010 of the German AGO Recommendations for the Diagnosis and Treatment of Early and Metastatic Breast Cancer - Chapter A: Surgery, Pathology and Prognostic Factors, Adjuvant and Neoadjuvant Therapy, Adjuvant Radiotherapy
}

\author{
Christoph Thomssen ${ }^{\mathrm{a}}$ Nadia Harbeck ${ }^{\mathrm{b}}$, on behalf of the AGO Breast Committee* \\ aUniversitätsfrauenklinik der Martin-Luther-Universität Halle-Wittenberg, Halle (Saale), \\ ${ }^{b}$ Department of OB/GYN, Breast Center, University of Cologne, Germany
}

\section{Introduction}

For the last 9 years, the Breast Committee of the German Gynecological Oncology Group (AGO) has published annually updated and evidence-based recommendations for the diagnosis and treatment of early and metastatic breast cancer. By now, these guidelines are well established and widely used by breast cancer specialists in and outside of Germany. The rating of evidence was performed according to the Oxford group proposals of levels of evidence (LoE; www.cebm.net) [1], whilst the AGO recommendations were made according to a well defined scale (AGO +/-; table 1$)$. In addition, we

\footnotetext{
*Members of the 'AGO Breast Committee' in alphabetical order: UteSusan Albert, Marburg; Ingo Bauerfeind, Landshut; Joachim Bischoff, Magdeburg; Jens Uwe Blohmer, Berlin; Klaus Brunnert, Osnabrück; Peter Dall, Lüneburg; Ingo J. Diel, Mannheim; Tanja Fehm, Tübingen; Nikos Fersis, Heidelberg; Michael Friedrich, Lübeck; Kay Friedrichs, Hamburg; Bernd Gerber, Rostock; Uwe-Jochen Göhring, Bonn; Volker Hanf, Fürth; Nadia Harbeck, Köln; Jens Huober, St. Gallen; Christian Jackisch, Offenbach; Wolfgang Janni, Düsseldorf; Walter Jonat, Kiel (DKH); Manfred Kaufmann, Frankfurt; Hans H. Kreipe, Hannover (DGP); Sibylle Loibl, Neu-Isenburg; Hans-Joachim Lück, Hannover Nicolai Maass, Aachen; Gunter von Minckwitz, Neu-Isenburg (Co-Chair); Volker Möbus, Frankfurt; Christoph Mundhenke, Kiel; Volkmar Müller, Hamburg; Ulrike Nitz, Mönchengladbach; Carsten Oberhoff, Essen; Mahdi Rezai, Düsseldorf; Achim Rody, Frankfurt; Anton Scharl, Amberg; Rita Schmutzler, Köln; Andreas Schneeweiß, Heidelberg (AIO); Ingrid Schreer, Kiel (DGS); Florian Schütz, Heidelberg; Peter Sinn, Heidelberg (Pathologie); Erich F. Solomayer, Homburg; Rainer Souchon, Tübingen (ARO); Elmar Stickeler, Freiburg; Christoph Thomssen, Halle (Chair); Michael Untch, Berlin.
}

published a patients' version of these recommendations in order to provide patients with the same information as their physicians. Here, we report on the 2010 update of the AGO recommendations. The full version of these guidelines is available as a PDF slide file at www.ago-online.de ('Leitlinien') [2]. We focus on differences to the 2009 recommendations, i.e. on updated and new recommendations with regard to surgery, pathology and prognostic factors, adjuvant and neoadjuvant therapy, and adjuvant radiotherapy.

\section{Breast Cancer Surgery}

Oncologic Aspects

A thorough preoperative diagnostic work-up including preoperative histology by image-directed needle biopsy and a detailed description of the extent of the suspicious lesion are required for planning breast surgery ( $\operatorname{LoE} 2 \mathrm{a} \mathrm{B}, \mathrm{AGO}+/+$ ). However, evidence is accumulating that routine magnetic resonance imaging (MRI) of the breast, even in the case of invasive lobular cancer, may not be beneficial since it causes more extensive breast surgery in a substantial proportion of women without providing any survival advantage (LoE $2 b \mathrm{~B}$, AGO +/-). Randomized controlled trials (RCTs) are needed to determine the clinical value of detecting additional disease that changes surgical treatment in women with apparently localized breast cancer. MRI is only recommended in patients with hereditary disease (LoE $4 \mathrm{C}, \mathrm{AGO}+$ ).

History and physical examination are good clinical practice and mandatory in every patient. Chest X-ray, liver ultrasound,

\section{KARGER}

Fax +497614520714

Information@Karger.de

www.karger.com
(C) 2010 S. Karger GmbH, Freiburg
Prof. Dr. med. Christoph Thomssen

Brustzentrum Halle, Zentrum für Frauenheilkunde und Geburtshilfe

Universitätsklink und Poliklinik für Gynäkologie

Ernst-Grube-Str. 40, 06097 Halle/Saale, Germany

Tel. +49 345 557-1847, Fax -1501

christoph.thomssen@medizin.uni-halle.de 
Table 1. AGO grades of recommendation, from Kommission 'Mamma' der Arbeitsgemeinschaft für Gynäkologische Onkologie e.V. (AGO) Guidelines 2010, Version 1.1 (www.ago-online.de [2])

\begin{tabular}{ll}
\hline$+/+$ & This investigation or therapeutic intervention is highly beneficial for patients, can be recommended without restriction, and should be \\
performed. & This investigation or therapeutic intervention is of limited benefit for patients and can be performed. \\
+ & This investigation or therapeutic intervention has not shown benefit for patients and may be performed only in individual cases. \\
$+/-$ & According to current knowledge, a general recommendation cannot be given. \\
- & This investigation or therapeutic intervention can be of disadvantage for patients and might not be performed. \\
$-/-$ & This investigation or therapeutic intervention is of clear disadvantage for patients and should be avoided or omitted in any case.
\end{tabular}

and bone scan have been used for the initial staging of breast cancer. However, these routine staging procedures may be beneficial for decision making only in patients at high risk for early metastasis, but not in low-risk breast cancer (clinically $\mathrm{T} 1$ and N0) (LoE $5 \mathrm{D}, \mathrm{AGO}+$ ).

Axillary dissection is mainly a diagnostic procedure. Removal of tumor-free lymph nodes increases morbidity and has no prognostic impact. Available evidence suggests that quality-assured sentinel lymph node excision (SLNE) is a reliable predictor for axillary lymph node status with high levels of sensitivity (90-95\%), specificity (100\%), negative predictive value (95\%), and accuracy (97\%). SLNE has become a standard surgical procedure in patients with clinically and sonographically negative axillae (cN0). Nowadays, the concept of SLNE is proven in many indications (e.g. cT2, multicentricity). In large ductal carcinomas in situ (DCIS), or if mastectomy is required due to DCIS, SLNE should be offered to the patient. For SLNE before or after neoadjuvant chemotherapy (NACT), a prospective study, the SENTINA trial, is currently performed in Germany. In male breast cancer patients, SLNE is also feasible and accurate in clinically node-negative disease.

There are only few reports about SLNE during pregnancy. The radioactive dosage of the applied radiocolloid is estimated to be very low and therefore not harmful for the fetus. Nothing is known about altered lymph drainage during pregnancy. In a letter to one of the authors (I.B.), the Bundesamt für Strahlenschutz stated that no fetal harm is expected after application of $11 \mathrm{MBq}$ on the day of surgery and that therefore no indication for termination of pregnancy is given. By performing an SLNE biopsy, a large proportion of patients with pregnancy-associated breast cancer may be spared the risk of a complete axillary lymph node dissection. Therefore, we also recommend the procedure as an option during pregnancy $(\mathrm{LoE} 3 \mathrm{C}, \mathrm{AGO}+)$.

In order to enable SLNE in patients with axillary lymph nodes that are suspicious according to clinical and sonographic assessment, histological diagnosis can be performed by fine needle biopsy or core biopsy of that node (LoE $3 \mathrm{~b}$ C, $\mathrm{AGO}+/-)$.

The standard surgical procedure for early breast cancer is breast conservation followed by radiation therapy. Ipsilateral breast tumor relapse rates should be lower than $10 \%$ after
10 years of follow-up. Randomized trials and clinical series of breast conservation report conflicting evidence relating to tumor size as a risk factor for local recurrence, although most studies report no association. There is little evidence to justify the use of tumor size alone as an exclusion criterion for breast conservation therapy. Survival rates after modified radical mastectomy are equivalent to those after radical mastectomy. Skin-sparing mastectomy (SSM) with or without conservation of the nipple-areola complex and autologous reconstruction is an oncologically safe treatment option in selected patients. Survival rates after modified radical mastectomy are equivalent to those after radical mastectomy according to Rotter-Halsted.

Excisional biopsy should be wire-guided if the lesion is not palpable, and specimen radiography should be performed. Radioguided occult lesion localization (ROLL) is a possible alternative to the commonly used wire-guided localization (WGL) of non-palpable breast lesions. Intratumoral injection of a radiotracer identifies both the primary tumor and the sentinel lymph nodes for intraoperative gamma probe-guided dissection. Intraoperative radiography or ultrasound are indicated in all cases of non-palpable lesions (Good Clinical Practice, GCP). In breast-conserving surgery, the margins of the specimen have to be tumor-free. There is no universal agreement on the width of the tumor-free margin. Re-excision is required for a close margin $<1 \mathrm{~mm}$ (for DCIS $<2 \mathrm{~mm}$ ) in paraffin section. Re-excision is recommended within a period of $<4$ weeks. Patients with involved margins, large tumor size, and/or a DCIS component are more likely to have residual disease on re-excision.

\section{Plastic Reconstructive Aspects after Mastectomy}

Recent publications concerning breast reconstruction (BR) deal with immediate reconstruction and related complications in general, and particularly due to postoperative radiotherapy. A second topic is implant BR and the use of titanized mesh, acellular dermis, and lipofilling to enhance and improve implant coverage. The controversy among advocates of the different methods of autologous BR (DIEP (deep inferior epigastric perforator) flap versus pedicled TRAM (transverse rectus abdominus myocutaneous; pTRAM)) continues without demonstrating an advantage of either method. The role of a so-called 'delay' is still under investigation. 
Surgical complications and the use of neoadjuvant bevacizumab was the topic of an oral presentation at the San Antonio Breast Cancer Conference 2009 with the conclusion that the use of tissue expanders could be problematic in patients treated with anti-angiogenesis therapy [3].

Kronowitz [4] from the M. D. Anderson Cancer Center in Houston, Texas, states an increasing acceptance of the socalled 'delayed-immediate breast reconstruction' in patients who desire BR and face the possibility of postmastectomy radiotherapy (PMRT). Using an expander for immediate BR after SSM as an adjustable scaffold helps to preserve the 3-dimensional shape of the breast skin envelope: if PMRT is not necessary, the patient can proceed with the initially intended method of BR; otherwise PMRT will be performed followed by expander removal and autologous BR.

In SSM and immediate BR, titanized extralight mesh (TiLOOP Bra ${ }^{\circledR}$, PFM Medical AG, Köln, Germany) and acellular dermal matrix (ADM; Epiflex ${ }^{\circledR}$, German Institute for Cellular and Tissular Replacement (DIZG), Berlin, Germany) are able to extend the necessary extent of the implant pocket and facilitate positioning of the implant. In the case of ADM, the thickness of the overlying tissue is enhanced while at the same time reducing the risk of wrinkling, a goal that can also be achieved with lipofilling as long as it is administered in small portions strictly to the subdermal layer.

A great number of publications still deal with autologous BR - mostly DIEP and free TRAM, but also SIEA (superficial inferior epigastric artery), TMG (transverse myocutaneous gracilis) and GAP (gluteal artery perforator) flaps. Most DIEP publications discuss preoperative computed tomography (CT) angiographic methods to reduce complications and operating room time, and clinical flap-monitoring procedures. Peeters et al. [5] advise using ultrasound as a tool to detect fat necrosis, thereby adding another $35 \%$ to the clinically diagnosed $14 \%$. Two publications with substantial numbers of patients deal with pTRAM (Kim et al. [6], 500 flaps) and good results [6]. Chun et al. [7] conclude presenting 105 bipedicled TRAMs: 'Bilateral pedicled TRAM flaps ... remain a safe and reliable procedure, with donor-site morbidity rates that are comparable to those of other BR techniques'. Atisha et al. [8] from Ann Arbor, Michigan, add new insight to the surgical delay procedure in pTRAM. Due to a retrospective cohort study on 112 pTRAMs the authors conclude that with a significant $\mathrm{p}$ value of 0.018 the delay group had definitively less ischemic complications $(6.6 \%)$ than the non-delay group with $17.6 \%$

\section{Pathology and Prognostic Factors}

\section{Pathology}

A modification was introduced into the pathology guidelines in order to cover the issue of adequate biopsy material for determining the HER2 status. It was reported that false-positive or -negative immunohistochemical labeling may occur in core biopsies. Discrepancy rates between 12 and $25 \%$ were found $[9,10]$. In a validation study done at Hannover Medical School on 533 breast cancer specimens with parallel HER2 analysis in the core biopsy and resection specimen, a concordance rate of $95 \%$ was established, exceeding the concordance rate for progesterone receptor (PR) (89\%; estrogen receptor (ER) $98 \%$ ). The discrepant cases included 4 with inter-observer disagreement that was corrected by review, 2 with DCIS labeling in the core biopsy, and 2 bifocal tumors (von Wasielewski and Kreipe, unpublished).

It is recommended that individual laboratories should validate their methods by parallel staining of core biopsies and resection specimens before immunohistochemical detection of HER2 is done on a routine basis on core biopsies (LoE $5 \mathrm{D}, \mathrm{AGO}+/+$ ). Attention needs to be paid to background staining in core biopsies, and tumor HER2 staining should be evaluated by comparison with staining of normal duct epithelium. If $\mathrm{a} \geq 95 \%$ concordance is achieved, the method could be considered validated. An alternative approach would be to reanalyze all G1 and G2 cases with HER2 3+ in core biopsies either by in situ hybridization (ISH) or by parallel staining of the resection specimen. In the case of a discrepancy between core biopsy and specimen, the HER2 overexpressing sample should be re-evaluated by a different method, either ISH or immunohistochemistry. If the discrepancy persists, HER2directed treatment could be considered if amplification is proven in at least one of the two samples.

\section{Prognostic and Predictive Factors}

In 2009, only a few study results regarding prognostic and predictive factors were presented that may have an additional impact on daily breast cancer patient care. A prospective cohort study of 1,897 breast cancer survivors diagnosed between 1997 and 2000 with a mean follow-up of 5.9 years suggested that regular alcohol intake of at least half a drink or more per day is associated with an increased risk of recurrence (hazard rate (HR) 1.34, 95\% confidence interval (CI) 1.0$1.82 ; \mathrm{p}=0.04$ ) and death from breast cancer (HR 1.51, 95\% CI 1.0-2.28; $\mathrm{p}=0.05)$, particularly among postmenopausal and overweight/obese women ( $\operatorname{LoE} 2 \mathrm{~b} \mathrm{~B}, \mathrm{AGO}+)$. However, confirmation in other large prospective studies is needed before any definite lifestyle recommendations can be made [11]. In addition, with a follow-up of 10 years, it was shown in 18,967 women from the Danish Breast Cancer Cooperative Group database that after adjustment for other prognostic factors, patients with a body mass index (BMI) over 25 had a significantly increased risk (42-46\%) of developing distant metastases and a significantly increased risk (26-38\%) of dying from breast cancer ( $\operatorname{LoE} 2 \mathrm{~b} \mathrm{~B}, \mathrm{AGO}+$ ). Adjuvant treatment seemed less effective in patients with a BMI of at least 30 [12]. 


\section{Adjuvant Systemic Therapy}

\section{Adjuvant Chemotherapy (Optimal Drugs / Optimal Dosage / Trastuzumab)}

Anthracyclines and taxanes are essential parts of adjuvant chemotherapy in primary breast cancer. In node-positive disease, taxanes are an evidence-based standard. In nodenegative disease, taxanes need to be considered in patients at high risk for relapse ( $\mathrm{LoE} 2 \mathrm{~b} \mathrm{~B}, \mathrm{AGO}+)$ as the GEICAM 9805 trial showed a significant improvement in disease-free survival for DocAC (docetaxel, doxorubicin, cyclophosphamide) vs. FAC (5-fluorouracil, doxorubicin, cyclophosphamide). If considering all risks (e.g. cardiac toxicity, secondary leukemia), and an anthracycline-containing regimen seems to be contraindicated, the anthracycline-free combination DocC is an evidence-based option [13]. However, the comparator arm in the US Oncology trial was merely $4 \times$ AC. Thus, participation in ongoing clinical trials (e.g. Plan B, SUCCESS C) which are currently evaluating non-anthracycline regimens in comparison to standard triplet combinations or anthracyclinetaxane sequences is strongly recommended. In high-risk node-positive disease with $>4$ involved lymph nodes, the dose-dense, dose-intensified ddETC (epirubicin, paclitaxel, cyclophosphamide) regimen provides a significant diseasefree survival advantage over a conventionally dosed anthracycline-taxane sequence ( $\mathrm{LoE} 1 \mathrm{~b} \mathrm{~B}, \mathrm{AGO}+/+$ ) [14]. This treatment should be performed in experienced centers only.

All primary breast cancers should be tested for HER2 expression since detection of HER2 overexpression or gene amplification is a prerequisite for trastuzumab therapy. Thorough external and internal quality control for HER2 testing is strongly recommended. In HER2-positive disease, benefit for adjuvant trastuzumab therapy has been demonstrated for node-negative and node-positive patients. Registration studies only included node-negative patients with tumors $>1 \mathrm{~cm}$. Yet, limited data suggests that patients with HER2positive tumors $<1 \mathrm{~cm}$ also have a substantially increased risk of recurrence compared to those with HER2-negative disease [15]. Therefore, in patients with tumors $>5 \mathrm{~mm}$ and additional risk factors, who are candidates for adjuvant chemotherapy, the use of trastuzumab can be considered (LoE $4 \mathrm{C}$, $\mathrm{AGO}+$ ). Based on the results of the registration trials, adjuvant trastuzumab may be used sequentially (LoE $2 b$ B, $\mathrm{AGO}+$ ) or concurrently with taxane chemotherapy. Recent evidence [16] suggests a substantial numerical advantage of concurrent use of trastuzumab with a taxane compared to sequential administration even though it is not significant after correction for multiple testing as stated in the study protocol. Thus, concurrent use ( $\mathrm{LoE} 2 \mathrm{~b} \mathrm{~B}, \mathrm{AGO}+/+$ ) of trastuzumab with taxane chemotherapy is preferable.

\section{Neoadjuvant Chemotherapy / Primary Systemic Therapy}

NACT is the current standard of care for patients with large, inoperable tumors or inflammatory disease. Several ran- domized trials have demonstrated in operable breast cancer that anthracycline- and taxane-containing regimens were equally effective regardless of whether they were administered postoperatively or preoperatively. Moreover, tumor response in terms of pathologic complete remission ( $\mathrm{pCR}$ ) after preoperative chemotherapy may serve as a short-term surrogate marker for long-term outcome. This theory is supported by the favorable long-term outcome which has been shown consistently for patients who achieved a pCR after NACT. Anthracycline- and taxane-based chemotherapy regimens have been extensively studied in RCTs and are the most frequently applied regimens in the neoadjuvant setting. Young patients with negative hormone receptor status, poor grading, non-lobular tumor type, and triple-negative phenotype have a high chance of achieving a pCR [17]. In a recently published analysis of the Gepartrio trial [18], no evidence of a difference in response to NACT was found by tumor stage when adjusted for baseline characteristics. Data for response prediction by gene expression profiles are not sufficiently robust to recommend them for use in clinical practice. For neoadjuvant endocrine treatment, low ER expression, high Ki-67 (> 10\%), and more advanced tumor stage were predictive for low sensitivity. Clinical examination, sonography, mammography, and MRI are possible methods of monitoring tumor response under NACT.

\section{Adjuvant Endocrine Therapy}

Prerequisites for adjuvant endocrine treatment are a valid determination of the menopausal status and a reliable test for endocrine sensitivity. Only patients with endocrine-responsive tumors should receive anti-hormonal treatment. As stated by the St. Gallen Consensus Panel, endocrine sensitivity is present if any tumor cells express either or both steroid hormone receptors (LoE 1a A, AGO +/+) [19-21].

\section{Premenopausal Patients}

Tamoxifen for 5 years is still considered standard endocrine therapy in all premenopausal women with endocrine sensitivity independent of prior adjuvant chemotherapy (LoE 1a A, $\mathrm{AGO}+/+$ ). The role of ovarian ablation or suppression in addition to tamoxifen is still unclear [22, 23]; therefore, adjuvant gonadotropin-releasing hormone $(\mathrm{GnRH})$ agonist therapy remains under active investigation (ongoing studies: SOFT = Suppression of Ovarian Function Trial; TEXT = Tamoxifen Exemestan trial). Chemotherapy followed by tamoxifen and 2-5 years GnRH agonists may be considered for certain subgroups ( $<40$ years; LoE 2a C, $\mathrm{AGO}+$ ).

In cases of relevant contraindications against tamoxifen, GnRH agonists alone were discussed as an option, but are not recommended by the AGO. Aromatase inhibitors are not indicated in premenopausal patients, not even in combination with GnRH agonists, after chemotherapy-induced amenorrhea or if relevant contraindications against tamoxifen exist (LoE 5 D, AGO -) [24, 25]. In the case of deep vein thrombo- 
sis, tamoxifen therapy accompanied by adequate anticoagulation may also be considered.

Since two RCTs were not able to show a significant effect, ovarian protection by $\mathrm{GnRH}$ agonists during chemotherapy cannot be recommended (LoE 1b B, AGO -) [26-29]. However, fertility preservation counseling is suggested in all patients who want to preserve their fertility (LoE $5 \mathrm{D}$, $\mathrm{AGO}+)$

\section{Postmenopausal Patients}

Adjuvant endocrine treatment of postmenopausal women can be performed in different ways:

1. Sequential approach $(\mathrm{AGO}+/+)$ : i) Tamoxifen for $2-3$ years followed by an aromatase inhibitor for 3-2 years (LoE 1a A). Sequential aromatase inhibitor treatment up to 5 years is not evidence-based and may be given only in special situations (LoE $5 \mathrm{D}, \mathrm{AGO}+/-$ ); ii) Aromatase inhibitor for 2-3 years followed by tamoxifen for 3-2 years (LoE1b C) with a preference for this approach in nodepositive disease (data only available for letrozole).

2. Upfront aromatase inhibitor $(\mathrm{AGO}+)$ : Aromatase inhibitor therapy upfront for 5 years $(\mathrm{LoE} 1 \mathrm{a} \mathrm{A}, \mathrm{AGO}+)$ is superior to tamoxifen for 5 years with regard to diseasefree survival. In both trials with adequate follow-up (ATAC, BIG 1-98), a survival benefit was not shown [30]. In BIG 1-98, the censored analysis (patients who crossed from tamoxifen to letrozol were censored) suggests a significant survival advantage for letrozole [31]. Interpretation of these results, however, is difficult; therefore, upfront approaches can only be recommended with regard to reduction of recurrences $(\mathrm{AGO}+)$.

3. Standard treatment with tamoxifen 5 years: Tamoxifen $20 \mathrm{mg} /$ day for 5 years is still a valid treatment option (LoE 1a $\mathrm{A}, \mathrm{AGO}+$ ). For patients treated with tamoxifen for 5 years, subsequent aromatase inhibitor therapy 3-5 years as extended endocrine treatment can be prescribed (extended adjuvant aromatase inhibitor therapy, EAT) (LoE 1b A, AGO +); in node-positive disease, a significant survival benefit was shown ( $\operatorname{LoE} 2 \mathrm{~b} B, A G O+/+)$. In a subgroup analysis, a substantial benefit of EAT was demonstrated also for patients who became postmenopausal during the 5 years of tamoxifen treatment (LoE 2b B, $\mathrm{AGO}+$ ) [32].

Ongoing studies for postmenopausal patients with hormone receptor-positive tumors are PREFACE (translational research), COMPACT, and EVALUATE (compliance).

\section{Bisphosphonates}

In some studies, adjuvant bisphosphonate treatment in primary breast cancer shows an improvement of disease-free survival in individual studies, also for overall survival (LoE $1 \mathrm{~b} C$, $\mathrm{AGO}+$ ). Evidence-based treatment options are clodronate (1,600 mg/day orally for 2 years) ( $\operatorname{LoE~} 1 \mathrm{~b}, \mathrm{Gr} \mathrm{B}, \mathrm{AGO}+)$, or zoledronate (5 mg intravenously every 6 months for 3 years), in postmenopausal ( $\mathrm{LoE} 3 \mathrm{~b} \mathrm{C}, \mathrm{AGO}+$ ) and in premenopausal patients $(\mathrm{LoE} 2 \mathrm{~b} \mathrm{C}, \mathrm{AGO}+)[24,33]$.

\section{Adjuvant Radiotherapy}

For both, adjuvant PMRT of the chest wall and radiotherapy of the breast after breast-conserving surgery, significant improvement of locoregional control as well as overall survival has been demonstrated $[34,35]$. These benefits are independent and additive to those of adjuvant systemic therapies and, with regard to PMRT, even significant for patients with 1-3 tumor-infiltrated lymph nodes (pN1a) [36-42] (LoE1a A, $\mathrm{AGO}+$ ). In contrast, the impact of PMRT in T3pN0 has been overestimated and seems to be marginal, particularly in patients who receive modern adjuvant systemic treatment (LoE $2 \mathrm{~b} \mathrm{~B}, \mathrm{AGO}+/-)$.

Modern radiotherapy should be based on CT-based treatment planning, electronic portal imaging devices etc. in order to improve accuracy and reproducibility of patient set-up, definition, and localization of clinical target volume as well as boost volume, homogeneity of dose distribution, and precision of set-up verification, although data from prospective trials or cohort studies are lacking. New concepts include: i) boost radiotherapy of the primary tumor region; ii) hypofractionation; iii) accelerated partial breast irradiation (APBI).

Pathological characteristics influencing local relapse after breast-conserving surgery or mastectomy have an important impact on application of radiotherapy [43]. A boost dose of 16 Gy significantly reduced the negative effects of both young age and high-grade invasive ductal cancer [44-46]. In DCIS, a minimal lesion-free margin of $2 \mathrm{~mm}$ should be obtained when breast-conserving surgery for DCIS is combined with radiotherapy [47-48].

Micrometastastic node positivity (pNmic) or isolated tumor cells in locoregional lymph nodes, known to be associated with poorer survival compared to $\mathrm{pN} 0$ disease, nowadays do not alter any indication for radiation therapy (LoE $2 b \mathrm{~B}$, AGO -/-) [49, 50]. Extracapsular tumor spread (ECS), which is not part of the TNM classification any more and only an optional information in the pathology report, and the risk of local, axillary, and supraclavicular recurrence in node-positive, premenopausal patients with breast cancer was investigated by the International Breast Cancer Study Group which came to the conclusion that the decision for additional regional radiotherapy should not be based solely on the presence of ECS ( $\mathrm{LoE} 2 \mathrm{~b} \mathrm{~B}, \mathrm{AGO}-/-$ ) [51]. The management of internal mammary nodes in breast cancer is controversial due to the lack of mature data. Two large randomized trials (French Group Trial ( $\mathrm{n}=1,334$ patients), European Organization for Research and Treatment of Cancer (EORTC) Trial 22922 ( $\mathrm{n}=4,004$ patients)) are currently evaluating the possible benefit of internal mammary irradiation. The updated 
NCCN Practice Guidelines recommend radiotherapy to the internal mammary nodes if internal mammary lymph nodes are clinically or pathologically positive. CT treatment planning should be utilized in all cases where radiation therapy is delivered to the internal mammary lymph node field (LoE 2b $\mathrm{C}, \mathrm{AGO}+/-)[38,52]$.

In the adjuvant situation, radiotherapy and trastuzumab can be given concomitantly ( $\mathrm{LoE} 2 \mathrm{~b} \mathrm{~B}, \mathrm{AGO}+$ ). Data from the North Central Cancer Treatment Group Phase III Trial N9831 as well as reports from mono-institutional studies show that concurrent adjuvant radiotherapy and trastuzumab for early-stage breast cancer was not associated with increased acute adverse events. There was no excess of acute cardiotoxicity observed with the combination of left-sided internal mammary irradiation and concurrent trastuzumab. Further follow-up is required to assess late adverse events [53].

In a second chapter, in the next issue of BREAST CARE, we will publish the updated AGO recommendations on prevention, early detection, life style; premalignant lesion, DCIS; recurrent and metastatic breast cancer. The next update of the AGO recommendations for the diagnosis and treatment of early and metastatic breast cancer is planned for January 2011.

\section{References}

1 Oxford Levels of Evidence. Oxford Centre for Evidence-based Medicine Levels of Evidence; March 2009 (for definitions of terms used see glossary at www.cebm.net/?o=1116). Produced by Bob Phillips, Chris Ball, Dave Sackett, Doug Badenoch, Sharon Straus, Brian Haynes, Martin Dawes since November 1998. Updated by Jeremy Howick March 2009.

2 www.ago-online.de ('Leitlinien')

3 Golshan M, Garber J, Gelman R, Tung N, Smith B, Troyan S, Greenberg C, Winer E, Ryan P: Surgical complications and the use of neoadjuvant bevacizumab. Cancer Res 2009;69:43.

$\checkmark 4$ Kronowitz SJ: Delayed-immediate breast reconstruction: technical and timing considerations. Plast Reconstr Surg 2010;125:463-74.

$\checkmark 5$ Peeters WJ, Nanhekhan L, Van Ongeval C, Fabré G, Vandevoort M: Fat necrosis in deep inferior epigastric perforator flaps: an ultrasound-based review of 202 cases. Plast Reconstr Surg 2009;124:1754-8.

6 Kim EK, Eom JS, Ahn SH, Son BH, Lee TJ: Evolution of the pedicled TRAM flap: a prospective study of 500 consecutive cases by a single surgeon in Asian patients. Ann Plast Surg 2009;63:378-82.

7 Chun YS, Sinha I, Turko A, Lipsitz S, Pribaz JJ Outcomes and patient satisfaction following breast reconstruction with bilateral pedicled TRAM flaps in 105 consecutive patients. Plast Reconstr Surg 2010;125:1-9.

$\checkmark 8$ Atisha D, Alderman AK, Janiga T, Singal B, Wilkins EG: The efficacy of the surgical delay procedure in pedicle TRAM breast reconstruction. Ann Plast Surg 2009;63:383-8.

9 Usami S, Moriya T, Amari M, Suzuki A, Ishida T, Sasano H, Ohuchi N: Reliability of prognostic factors in breast carcinoma determined by core needle biopsy. Jpn J Clin Oncol 2007;37:250-5.

10 Erggelet J, Große R, Holzhausen HJ, Hauptmann $\mathrm{S}$, Thomssen C: Correlation of human epidermal growth factor receptor 2 (HER2), estrogen receptor (ER), and progesterone receptor (PR) expression as predicted by core biopsy with the immunohistochemical results of surgical breast cancer specimens. Breast Care 2007;2:94-8.

11 Brennan ME, Houssami N, Lord S, Macaskill P, Irwig L, Dixon M, Warren, R, Ciatto S: Magnetic resonance imaging screening of the contralateral breast in women with newly diagnosed breast cancer: systematic review and meta-analysis of incremental cancer detection and impact on surgical management. JCO 2009;27:5640-9.
12 Alpert TE, Kuerer HM, Arthur DW, Lannin DR, Haffty BG: Ipsilateral breast tumor recurrence after breast conservation therapy: outcomes of salvage mastectomy vs. salvage breast-conserving surgery and prognostic factors for salvage breast preservation. Int J Radiat Oncol Biol Phys 2005;63:845-51.

13 Jones S, Holmes FA, O'Shaughnessy J, Blum JL, Vukelja SJ, McIntyre KJ, Pippen JE, Bordelon JH, Kirby RL, Sandbach J, Hyman WJ, Richards DA, Mennel RG, Boehm KA, Meyer WG, Asmar L, Mackey D, Riedel S, Muss H, Savin MA: Docetaxel with cyclophosphamide is associated with an overall survival benefit compared with doxorubicin and cyclophosphamide: 7-year followup of US Oncology Research Trial 9735. J Clin Oncol 2009;27:1177-83.

14 Moebus V, Jackisch C, Lueck HJ, du Bois A, Thomssen C, Kurbacher C, Kuhn W, Nitz U, Schneeweiss A, Huober J, Harbeck N, von Minckwitz G, Runnebaum IB, Hinke A, Kreienberg R, Konecny GE, Untch M: Intense dose-dense sequential chemotherapy with epirubicin, paclitaxel, and cyclophosphamide compared with conventionally scheduled chemotherapy in high-risk primary breast cancer: mature results of an AGO phase III study. J Clin Oncol 2010;28:2874-80.

15 Gonzalez-Angulo AM, Litton JK, Broglio KR, Meric-Bernstam F, Rakkhit R, Cardoso F, Peintinger F, Hanrahan EO, Sahin A, Guray M, Larsimont D, Feoli F, Stranzl H, Buchholz TA, Valero V, Theriault R, Piccart-Gebhart M, Ravdin PM, Berry DA, Hortobagyi GN: High risk of recurrence for patients with breast cancer who have human epidermal growth factor receptor 2-positive, node-negative tumors $1 \mathrm{~cm}$ or smaller. J Clin Oncol 2009;27:5700-6.

16 Perez EA, Suman VJ, Davidson NE, Gralow J, Kaufman PA, Ingle JN, Dakhil SR, Zujewski JA, Pisansky TM, Jenkins RB: Results of chemotherapy alone, with sequential or concurrent addition of 52 weeks of trastuzumab in the NCCTG N9831 HER2-Positive Adjuvant Breast Cancer Trial. SABCS 2009; abstr 80.

17 Von Minckwitz G, Kaufmann M, Kummel S, Fasching P, Eiermann W, Blohmer J, Costa SD, Sibylle L, Dietmar V, Untch M: Integrated metaanalysis on 6402 patients with early breast cancer receiving neoadjuvant anthracycline-taxane +/trastuzumab containing chemotherapy. Cancer Res 2009;69:79.
8 Costa SD, Loibl S, Kaufmann M, Zahm DM, Hilfrich J, Huober J, Eidtmann H, du Bois A, Blohmer JU, Ataseven B, Weiss E, Tesch H, Gerber B, Baumann KH, Thomssen C, Breitbach GP, Ibishi S, Jackisch C, Mehta K, von Minckwitz G: Neoadjuvant chemotherapy shows similar response in patients with inflammatory or locally advanced breast cancer when compared with operable breast cancer: a secondary analysis of the GeparTrio trial data. J Clin Oncol 2010;28:83-91.

19 Early Breast Cancer Trialists' Collaborative Group (EBCTCG): Effects of chemotherapy and hormonal therapy for early breast cancer on recurrence and 15-year survival: an overview of the randomised trials. Lancet 2005;365:1687-717.

20 Colleoni M, Gelber S, et al.; International Breast Cancer Study Group: Tamoxifen after adjuvant chemotherapy for premenopausal women with lymph node-positive breast cancer: International Breast Cancer Study Group Trial 13-93. J Clin Oncol 2006;24:1323-5.

21 Thürlimann B, Price KN, et al.: Is chemotherapy necessary for premenopausal women with lowerrisk node-positive, endocrine responsive breast cancer? 10-year update of International Breast Cancer Study Group Trial 11-93. Breast Cancer Res Treat 2009;113:137-44.

22 Cuzick J, Ambroisine, et al.; LHRH Agonists in Early Breast Cancer Overview Group: Use of luteinising-hormone-releasing hormone agonists as adjuvant treatment in premenopausal patients with hormone-receptor-positive breast cancer: a metaanalysis of individual patient data from randomised adjuvant trials. Lancet 2007:369:1711-23.

23 Hackshaw A, Baum M, et al.: Long-term effectiveness of adjuvant goserelin in premenopausal women with early breast cancer. J Natl Cancer Inst 2009;101:341-9.

24 Gnant M, Mlineritsch B, et al.: Endocrine therapy plus zoledronic acid in premenopausal breast cancer. N Engl J Med 2009;360:679-91.

25 Smith IE, Dowsett M, et al.: Adjuvant aromatase inhibitors for early breast cancer after chemotherapy-induced amenorrhoea: caution and suggested guidelines. J Clin Oncol 2006;24:2444-7.

26 Gerber B, Dieterich M, Muller H, Reimer T: Controversies in preservation of ovary function and fertility in patients with breast cancer. Breast Cancer Res Treat 2008;108:1-7. 
27 Badawy A, Elnashar A, El Ashry M, Shahat M: Gonadotropin-releasing hormone agonists for prevention of chemotherapy-induced ovarian damage: prospective randomized study. Fertil Steril 2009;91:694-7.

28 Gerber B, Stehle H, et al.: ZORO: A prospective randomized multicenter study to prevent chemotherapy induced ovarian failure with the GnRHagonist goserelin in young hormone insensitive breast cancer patients receiving anthracycline containing (neo-)adjuvant chemotherapy. J Clin Oncol 2009;27:abstr 526

29 Ismail-Khan R, Minton S, Cox C, et al.: Preservation of ovarian function in young women treated with neoadjuvant chemotherapy for breast cancer: a randomized trial using the GNRH agonis (triptorelin) during chemotherapy. J Clin Oncol 2008;26(suppl 1):12s(abstr 524).

-30 Dowsett M, Cuzick J, Ingle J, Coates A, Forbes J, Bliss J, Buyse M, Baum M, Buzdar A, Colleon M, Coombes C, Snowdon C, Gnant M, Jakesz R, Kaufmann M, Boccardo F, Godwin J, Davies C, Peto R: Meta-analysis of breast cancer outcomes in adjuvant trials of aromatase inhibitors versus tamoxifen. J Clin Oncol 2010;28:509-18.

-31 Mouridsen H, Giobbie-Hurder A, Goldhirsch A, Thürlimann B, Paridaens R, Smith I, Mauriac L, Forbes JF, Price KN, Regan MM, Gelber RD, Coates AS; BIG 1-98 Collaborative Group: Letrozole therapy alone or in sequence with tamoxifen in women with breast cancer. $\mathrm{N}$ Engl J Med 2009;361:766-76.

32 Goss P, Ingle J, Martino S, Robert N, Muss H, Shepherd L, Pritchard K, Livingston R, Davidson N, Perez E, Cameron D, Whelan T, Palmer M, Tu D: Outcomes of women who were premenopausal at diagnosis of early stage breast cancer in the NCIC CTG MA17 Trial. Cancer Res 2010;69:13.

-33 Diel IJ, Jaschke A, Solomayer EF, Gollan C, Bastert G, Sohn C, Schuetz F: Adjuvant oral clodronate improves the overall survival of primary breast cancer patients with micrometastases to the bone marrow: a long-term follow-up. Ann Oncol 2008;19:2007-11.

-34 Benson JR, Jatoi I, Keisch M, Esteva FJ, Makris A, Jordan VC: Early breast cancer. Lancet 2009;373:1463-79, review.

35 Buchholz TA: Radiation therapy for early-stage breast cancer after breast-conserving surgery. $\mathrm{N}$ Engl J Med 2009;360:63-70, review.

36 Darby S, on Behalf of the Early Breast Cancer Trialists' Collaborative Group: Overview of the Randomised Trials of Radiotherapy in Early Breast Cancer. Cancer Res 2010;69(24 suppl):abstr MS3-1
37 Macdonald SM, Abi-Raad RF, Alm El-Din MA, Niemierko A, Kobayashi W, McGrath JJ, Goldberg SI, Powell S, Smith B, Taghian AG: Chest wall radiotherapy: middle ground for treatment of patients with one to three positive lymph nodes after mastectomy. Int J Radiat Oncol Biol Phys 2009;75:1297-303.

38 NCCN (National Comprehensive Cancer Network): Clinical Practice Guidelines in Oncology: Breast Cancer - version V.1. 2010.

39 Rowell NP: Radiotherapy to the chest wall following mastectomy for node-negative breast cancer: a systematic review. Radiother Oncol 2009;91:23-32.

40 Tai P, Yu E, Sadikov E, Joseph K: A long-term study of radiation therapy in T1-2 node-negative breast cancer patients in relation to the number of axillary nodes examined. Int J Radiat Oncol Biol Phys 2009;74:453-7.

41 Truong PT, Jones SO, Kader HA, Wai ES, Speers $\mathrm{CH}$, Alexander AS, Olivotto IA: Patients with $\mathrm{t} 1$ to 2 breast cancer with one to three positive nodes have higher local and regional recurrence risks compared with node-negative patients after breastconserving surgery and whole-breast radiotherapy. Int J Radiat Oncol Biol Phys 2009;73:357-64.

42 Voordeckers M, Vinh-Hung V, Lamote J, Bretz A, Storme G: Survival benefit with radiation therapy in node-positive breast carcinoma patients. Strahlenther Onkol 2009:185:656-62.

43 Jones HA, Antonini N, Hart AA, Peterse JL, Horiot JC, Collin F, Poortmans PM, Oei SB, Collette L, Struikmans H, Van den Bogaert WF, Fourquet A, Jager JJ, Schinagl DA, WárlámRodenhuis CC, Bartelink H: Impact of pathological characteristics on local relapse after breast-conserving therapy: a subgroup analysis of the EORTC Boost Versus No Boost Trial. J Clin Oncol 2009;27:4939-47.

44 Poortmans PM, Collette L, Horiot JC, Van den Bogaert WF, Fourquet A, Kuten A, Noordijk EM, Hoogenraad W, Mirimanoff RO, Pierart M, Van Limbergen E, Bartelink $\mathrm{H}$; on behalf of the EORTC Radiation Oncology and Breast Cancer Groups: Impact of the boost dose of 10 Gy versus 26 Gy in patients with early stage breast cancer after a microscopically incomplete lumpectomy: 10-year results of the randomised EORTC boost trial. Radiother Oncol 2009;90:80-5.

45 Livi L, Borghesi S, Saieva C, Fambrini M, Iannalfi A, Greto D, Paiar F, Scoccianti S, Simontacchi G, Bianchi S, Cataliotti L, Biti G: Benefit of radiation boost after whole-breast radiotherapy. Int J Radiat Oncol Biol Phys 2009;75:1029-34.
6 Collette S, Collette L, Budiharto T, Horiot JC, Poortmans PM, Struikmans H, Van den Bogaert W, Fourquet A, Jager JJ, Hoogenraad W, Mueller RP, Kurtz J, Morgan DA, Dubois JB, Salamon E, Mirimanoff R, Bolla M, Van der Hulst M, WárlámRodenhuis CC, Bartelink H; EORTC Radiation Oncology Group: Predictors of the risk of fibrosis at 10 years after breast conserving therapy for early breast cancer: a study based on the EORTC Trial 22881-10882 'boost versus no boost'. Eur J Cancer 2008;44:2587-99.

47 Goodwin A, Parker S, et al.: Post-operative radiotherapy for ductal carcinoma in situ of the breast a systematic review of the randomised trials. Breast 2009;18:143-9.

48 Dunne C, Burke JP, et al.: Effect of margin status on local recurrence after breast conservation and radiation therapy for ductal carcinoma in situ. J Clin Oncol 2009;27:1615-20.

49 De Boer M, van Deurzen CH, van Dijck JA, Borm GF, van Diest PJ, Adang EM, Nortier JW, Rutgers EJ, Seynaeve C, Menke-Pluymers MB, Bult P, Tjan-Heijnen VC: Micrometastases or isolated tumor cells and the outcome of breast cancer. N Engl J Med 2009;361:653-63.

50 Tjan-Heijnen VC, de Boer M: Minimal lymph node involvement and outcome of breast cancer. The results of the Dutch MIRROR study. Discov Med 2009;8:137-9.

51 Gruber G, Cole BF, Castiglione-Gertsch M, Holmberg SB, Lindtner J, Golouh R, Collins J, Crivellari D, Thürlimann B, Simoncini E, Fey MF, Gelber RD, Coates AS, Price KN, Goldhirsch A, Viale G, Gusterson BA; International Breast Cancer Study Group: Extracapsular tumor spread and the risk of local, axillary and supraclavicular recurrence in node-positive, premenopausal patients with breast cancer. Ann Oncol 2008:19:1393-1401.

52 Romestaing P, Belot A, Hennequin C, Bosset J, Maingon P, Dubois J, Bossard N, Gerard J: Tenyear results of a randomized trial of internal mammary chain irradiation after mastectomy. Int $\mathrm{J}$ Radiat Oncol Biol Phys 2009;75(suppl S1):abstr S1.

53 Halyard MY, Pisansky TM, Dueck AC, Suman V, Pierce L, Solin L, Marks L, Davidson N, Martino S, Kaufman P, Kutteh L, Dakhil SR, Perez EA: Radiotherapy and adjuvant trastuzumab in operable breast cancer: tolerability and adverse event data from the NCCTG Phase III Trial N9831. J Clin Oncol 2009;27:2638-44. 